revista ANTHROPOLÓGICAS

Ano 24, 31(2): 122-152, 2020

\title{
O Aurora e a Prática do Sem Preço: Reflexões sobre política, infraestrutura e dinheiro na vida ordinária ${ }^{1}$
}

Yuri Rosa Neves ${ }^{a}$

O artigo analisa $o$ ato de pagar a partir da discussão antropológica sobre infraestruturas. Mais especificamente, apoia-se em ferramentas conceituais que apontam para a dimensão ordinária, banal e invisível com a qual as infraestruturas se revelam para as pessoas em suas interações. A reflexão é enriquecida por um caso empírico em que este itinerário burocrático de consumo, pagar por algo, acontece de modo diferente: um restaurante em que a refeição não tem um preço fixo, pré-estabelecido ou mesmo sugerido. $\mathrm{O}$ Aurora propõe o 'sem preço' como uma prática de 'corresponsabilização e apoio mútuo por entender o valor relativo do dinheiro em nossa sociedade. O efeito de contraste com o 'normal' que tal experiência engaja permite aprofundar nossos comprometimentos naturalizados com as lógicas de funcionamento das infraestruturas através do intercâmbio constante entre materialidade e ideologia no qual somos sempre agentes e sujeitos.

Infraestrutura, Cotidiano, Dinheiro, Consumo, Ação Política.

\section{Infraestrutura, dinheiro e consumo}

Quem quiser empreender o que quer que seja contra o mundo existente deve partir dai: a verdadeira estrutura de poder é a organização material, tecnológica, física deste mundo. O governo já não está no governo. (Comitê Invisível, $\mathrm{O}$ poder é logístico. Bloqueemos tudo. In Aos nossos amigos: crise e insurreição, 2016).

O dinheiro está em todos os lados. E o que tem de banal sobre ele, tem de importância na vida das pessoas. Por isso, é um objeto

a Doutorando em Antropologia - PPGA/UFPE. Email: nevyuri@gmail.com. 
de debates calorosos na vida pública. Neste artigo, proponho-me a refletir sobre uma forma de uso do dinheiro: o ato de pagar. Mais especificamente, pagar por uma refeição num restaurante. Para realizar esta tarefa, vou me basear num caso empírico no qual esta dimensão é amplificada criando um efeito de contraste ou descontinuidade no modo como esse momento do itinerário de consumo é normalmente vivido: trata-se de um restaurante em que a maioria das refeições não tem um preço pré-estabelecido. O 'sem preço', como seus idealizadores o chamam, “... representa uma prática de uma troca sincera e a formação de uma relação de confiança” ${ }^{3}$.

Esta estratégia argumentativa e metodológica focando sobre formas de realizar atividades banais de formas heterodoxas remete à minha pesquisa com a prática de carona espontânea na cidade de Florianópolis (Neves 2018a). Assim como nessa pesquisa anterior, o que pretendo explorar neste artigo se beneficia da perspectiva antropológica sobre as infraestruturas pela articulação entre a materialidade e dimensão ordinária na experiência das pessoas. Água encanada na torneira, eletricidade na tomada, sistemas bancários na palma da nossa mão, recolhimento de lixo, ônibus e até mesmo o Uber são relações constantes com redes de infraestruturas a tal ponto naturalizadas que suas funcionalidades são sempre tomadas por certas. Algumas potentes ferramentas conceituais foram e estão sendo desenvolvidas neste debate relativamente recente na antropologia para pensar esta questão.

Provavelmente a mais repetida ideia, sintetizada na seminal contribuição de Star (1999), seja a de que as infraestruturas são intencionalmente projetadas para funcionar de modo invisível, como um fundo ou cenário (background), a menos que elas colapsem (breakdown) e se mostrem visíveis. Um cano que estoura, a luz, a internet que cai ou o lixo que não é recolhido. Estes são momentos em que parte de sua extensão fica visível (Star 1999:382). Tendo a compreender esta ideia como um conceito de médio alcance que ganha força articulado com outras noções. Como sugere Larkin, não se pode tomar como 
algo simplesmente inerente e dado, "... mas examinar como a (in)visibilidade é mobilizada e porquê” (Larkin 2013:336). Ainda seguindo a definição da autora, encontramos algumas direções para pensar este 'como' e este 'porquê' em relação ao objetivo do artigo.

Primeiro, os "trabalhos invisíveis" (Star 1999:385) que mantêm tudo funcionando de maneira mais suave para a experiência do usuário. No caso empírico em foco, trabalhadores e trabalhadoras na cozinha, nos transportes de mercadorias, nos mercados e feiras são alguns dos exemplos de atividades invisíveis à experiência de cliente de um restaurante. Além disso, a remuneração e as despesas desses trabalhos invisíveis estão, em tese, no preço da comida e do serviço. Segundo, Star discute a "incorporação de padrões" (Star 1999:381-2), que se articula com o tericeiro ponto, o fato de que aprendemos a utilizar e interagir com as infraestruturas a partir da participação numa comunidade de práticas (Star 1999:381). Isto implica com que não seja tanto um conhecimento escolástico, bem refletido na interação cotidiana, engajamo-nos e praticamos para aprender como utilizar. E, por fim, a 'transparência', ou seja, o fato de não se precisar reinventar os processos para cada uso. Uma vez estabelecida a infraestrutura, ela dá "suporte invisível" às tarefas programadas (Star 1999:381). Há outros aspectos levantados por Star, porém destaquei esses por contribuírem com mais força para a ideia do argumento. Ocasionalmente eles serão mobilizados.

A ideia de invisibilidade também traz à superfície a complexa relação entre os dois atores sociais implicados em qualquer infraestrutura: o técnico ou expert que cria o projeto e pensa a modelagem da infraestrutura para o usuário, e, na outra ponta, as pessoas que a utilizam. Nessa interação entre planejadores, materialidade e pessoas sempre emergem descontinuidades, que não necessariamente comprometem a funcionalidade, mas exibem a multiplicidade de experiência de usos, de acessos e de limites. Smith (2016) argumenta que podemos compreender esta interação pela produção de "consenso" num "diálogo materializado" (Smith 2016:167) inevitavelmente impreciso 
entre aquilo que é planejado e como é usado (Smith 2016:166). Pensando no desenvolvimento das cidades, ela mobiliza uma discussão sobre "tomada de turnos" num sentido material do discurso (Smith 2016:168) baseado numa perspectiva de que linguagem é em si uma infraestrutura das instituições sociais (Schegloff 2006), trazendo então uma noção mais performativa do que semiótica dos significados das infraestruturas. A autora sugere como o crescimento das cidades e a aceleração da produção e do consumo produziram infraestruturas com as quais "indivíduos de todas as classes criaram um ethos urbano através do engajamento material nas práticas cotidianas” (Smith 2016:166).

A interação dentro de um restaurante e até com os serviços em geral pode ser vista como expressão desse tipo de ethos. A existência de cardápios, propagandas, catálogos e sinais com o preço dos produtos possibilita um diálogo entre cliente e estabelecimento no qual a fala é dispensável. Além disso, esta pequena parte do itinerário de interação no consumo é tão imbricada na concepção contemporânea de cidade e de vida a ponto de ser possível criar esse entendimento mesmo quando se está num país de língua completamente desconhecida. A 'transparência' e a 'incorporação de padrões' funcionam bem neste caso. Não por acaso, na reflexão fundante de Simmel sobre cidades para a antropologia e sociologia, ele coloca o dinheiro como mediador das trocas e representativo da postura 'intelectualista' e 'blasé' do citadino em contraposição ao anima do habitante rural (Simmel [1908]). O dinheiro pode não ser uma infraestrutura por si próprio, mas circula em todas os pontos dela: no planejamento, na execução, na remuneração de trabalhadores e trabalhadoras, no cálculo da gestão e, não menos importante, no pagamento pelo serviço ${ }^{5}$. E, neste sentido, se pode parecer forçado considerar restaurantes uma infraestrutura, basta imaginar a circulação do dinheiro num estabelecimento comercial para que as relações entre as cadeias produtivas e com os diferentes "regimes infraestruturais" emerjam (Star 1999:380).

Um dos elementos que irei explorar ao longo do artigo é o que fazemos com a consciência sobre os efeitos performativos desses arran- 
jos materiais e dos seus itinerários de interação; ou seja, o que fazemos depois de visibilizar relações materiais e ideológicas que sustentam seu funcionamento de forma relativamente obviada? Para onde nos leva? No restaurante Aurora, em vez de uma pessoa no caixa, há uma balança de pratos antiga em que deixamos o dinheiro e fazemos o troco sem supervisão. Informativos sobre as mesas mostram porcentagens de metas e balanços financeiros, o funcionamento dos pedidos e o que pretende o sem preço. Como mencionei anteriormente, ele é proposto como uma prática de 'corresponsabilização e apoio mútuo' que leva em conta o fato de o dinheiro ter um valor diferente para as pessoas em cada situação. Assim, sugerem que a pessoa pense no preço considerando, além do serviço e da comida, o seu contexto particular.

Essa questão vai nos encaminhando para um último ponto que gostaria de discutir nesta introdução: como a intencionalidade da modelagem (composta também pela questão de como se tornar natural e suave na experiência) é motivada por razões que transcendem a materialidade e a funcionalidade singular de uma infraestrutura. As mais óbvias e impregnadas em todo entendimento contemporâneo de infraestrutura são a racionalidade econômica, de governo e burocrática. O desenvolvimento das cidades e dos ideais de cidades, por exemplo, historicamente acompanharam as reestruturações dos modos de produção capitalista concebendo toda interconexão necessária à expansão do consumo quando demandada (Graham \& Marvin 2001:66-90). Do mesmo modo, serviu ao governo das populações pelo Estado para criar dados, cobrar impostos, prevenir aglomerações que atentem à ordem pública e etc. Como sugere Scott (1998) com o conceito de 'legibilidade', o Estado moderno fundou uma inteligência gerencial para objetos e populações a partir de modelos racionais e organizações materiais que, apesar de intencionalmente almejarem a naturalização e o sentido de invisibilidade para as pessoas, para si foi um dar visibilidade sobre as coisas. Ademais, ambas racionalidades econômica e de governo tendem a ser justificadas como técnicas e neutras, assim como a burocrática (Herzfeld 1992; Weber 1972). Es- 
ses registros, seus modelos e princípios, animam as infraestruturas e a nossa compreensão delas.

Se de um lado há a intencionalidade dos técnicos e teóricos nessa modelagem material, do outro, estamos nós, sujeitos e agentes nessa interação. Larkin (2013), após reconhecer esses aspectos de governo nas infraestruturas (Larkin 2013:329), explora como estas "nos formam como sujeitos não somente num nível tecnopolítico, mas também através de mobilizações de afeto e sentidos de desejo, orgulho, e frustração, sentimentos que podem ser profundamente políticos" (Larkin 2013:333). Assim, se as utilizamos, somos utilizados e nos afetamos pelas infraestruturas num nível subjetivo, interagimos com a sua intencionalidade e a sua carga ideológica e teórica. E, se há uma parte desse processo que acontece inconscientemente através da naturalização de hábitos e do povoamento da nossa imaginação, sujeitos da modelagem, como sugere Larkin, parte da aderência subjetiva se manifesta num nível consciente e eventualmente mobiliza princípios que se ligam à modelagem, seja como uma defesa ou como uma crítica. Assim, essa interação sendo sempre uma via de mão dupla, somos agentes não só dando contornos reais aos modos de usos da materialidade, mas também em relação às ideias norteadoras da intencionalidade tais quais o caráter de invisibilidade, funcionalidade, neutralidade e naturalização.

Este artigo se propõe a pensar esse processo de tomada consciente deste intercâmbio entre materialidade e ideologia, em que somos sempre agentes e sujeitos em ambas as esferas. Captar essa dinâmica fica mais nítido se pensarmos na separação conceitual e metodológica trazida por Boltanski \& Chiapelllo (2009) ao discutirem a emergência de um 'novo espírito' capitalista. Partindo da reestruturação de corpus discursivos sobre administração de empresas entre os 60 e os 90, esses autores introduzem uma separação entre capitalismo e o seu espírito, entendendo o primeiro como sistema produtivo que visa acumulação ilimitada, algo que poderíamos dizer é profundamente infraestrutural, e o segundo pela “...ideologia que justifica o engajamento no capi- 
talismo" (Boltanski \& Chapello 2009:39). O espírito tem o papel de trazer freios morais à expansão material ilimitada e despreocupada de qualquer esfera moral. Deste modo, uma interação entre um arranjo produtivo, que é material, e a dimensão ideológica, que é afetiva, subjetiva, alimenta nossa imaginação e, ocasionalmente, nos impele a dar justificativas sobre. Esses autores têm um interesse teórico sobre o papel da crítica neste processo dinâmico de transformação da justificação do engajamento no capitalismo. Mesmo sabendo que esses autores identificam diferentes modelos ou regimes de justificação, neste artigo me concentrarei na ideia geral já que o caso empírico o qual vou abordar, pelas descontinuidades neste itinerário burocratizado, faz emergir esse jogo de justificativas e críticas muito condizente com as ideias dos autores.

O Aurora, além de se definir como anticapitalista, se diz antiespecista, portanto, não utiliza nenhum derivado animal. Na primeira metade de 2018, época em que frequentava o lugar, conversei com os integrantes do coletivo sobre a proposta de fazer um trabalho refletindo essa experiência. $\mathrm{Na}$ época se chamava Germina e era composto por seis integrantes. Ainda naquele ano, após dois anos de funcionamento e concomitante à minha aproximação e proposta de pesquisa, houve uma mudança no nome do restaurante/coletivo para Aurora e uma diminuição de membros encabeçando a proposta, porém mantendo o mesmo esquema do sem preço e da estrutura de funcionamento do lugar. Portanto, devido ao momento de coleta de dados, minha reflexão utiliza materiais informativos e situações referentes ao tempo do Germina, mas usarei o nome Aurora. Além desses materiais que explicitam a intencionalidade do restaurante com suas escolhas administrativas, vou utilizar momentos de conversas mais ou menos dirigidas com os remanescentes do Germina para o Aurora e uma polêmica gerada no Facebook no dia primeiro de abril daquele ano quando o coletivo postou que estava com dificuldades financeiras para fechar o mês e pedia apoio aos seus colaboradores e colaboradoras. Essa situação permitiu pensar melhor os efeitos da proposta. 


\section{O invisível e o exótico}

O Aurora, à primeira vista, pode parecer com muitos outros pequenos restaurantes que reformam ambientes de antigas casas num bairro tradicional de uma capital ou grande cidade do país. Possui um pátio externo pequeno bastante agradável na frente com várias cadeiras coloridas rodeadas com plantas, e até uma banheira antiga é utilizada como vaso. As bicicletas de clientes e de pessoas que trabalham entregando refeições ficam ao lado direito, onde, mais no fundo, como numa espécie de pequena garagem aberta, se pode ver algumas ferramentas penduradas na parede num estojo com vários bolsos. Acima diz que o uso é livre, logo, requer cuidado das pessoas que as usarem.

Entrando na área interna comum do restaurante, vemos sete mesas de tamanhos e estilos variados cabendo de duas a sete pessoas. Oposto à entrada, há uma espécie de balcão no qual se pode ver a cozinha ao fundo e onde pedimos a comida. No lado direito, ao lado deste balcão, há uma espécie de área de espera com poltronas de um antigo cinema da cidade em frente a um outro balcão, o de atendimento. Nesse ambiente alguns clientes esperam mesas desocuparem, conversam, jogam vídeo game (um antigo Super Nintendo plugado numa TV pequena) ou comem em dias de muito movimento. Sobre o balcão de atendimento fica uma máquina registradora antiga, uma caixa de paçoca e uma balança de prato onde as pessoas deixam o dinheiro para pagar e fazem seu troco. As paredes são cheias de informação com cartazes, quadros, frases, desenhos, bandeiras, livros, brinquedos, objetos antigos, e a porta do porta-malas de uma Belinda é usada para escrever o cardápio do dia sobre o vidro. Este também é divulgado com antecedência pelo Facebook e Instagram.

Sobre todas as mesas há dois informativos. Um deles fala da proposta de um restaurante antiespecista e anticapitalista criticando uma sociedade que mata os animais e fecha as portas para minorias e pessoas sem dinheiro. Esse informativo também descreve como funcionam os procedimentos do pedido: a comida é livre, mas para evitar 
desperdícios, cada cliente pode escolher entre três tamanhos de pratos (reduzido, bem servido e canhão) e pedir mais quantas vezes quiser. Normalmente as pessoas vão diretamente até o balcão da cozinha e pedem aquilo que querem e a quantidade na hora de repetir. O outro informativo se propõe a dar transparência do balanço econômico do restaurante no período de um ano, justificando-se essa atitude como parte da proposta de 'corresponsabilização e cooperação mutua'. Apesar de não trazer números, apresenta gráficos comparando o número de refeições e a variação de entrada de dinheiro comparados com limites do que seriam situações ideais e insustentáveis.

Depois de já ter frequentando o Germina com regularidade há alguns meses, pois estava morando próximo, conversei com alguns membros do coletivo sobre a pesquisa. Disseram-me que teria de mandar um e-mail com a proposta, como estava indicado na página do Germina na internet, pois isso passaria pela reunião do coletivo. Depois de algumas semanas sem resposta, aproveitei o momento em que fui deixar o prato no balcão da cozinha e perguntei para o Alan Chaves se havia uma previsão para o coletivo considerar a proposta. Ele disse que eu precisava esperar eles conversarem sobre isso numa de suas reuniões semanais às segundas; era preciso haver consenso. Disse que estava corrido, uma pessoa do coletivo estava viajando e havia uma nova rotação da função de comunicação por e-mail sendo implementada. Pediu que eu reenviasse a proposta. Obviamente o ritmo de trabalho de um restaurante não abre muita margem para questões paralelas como essa. Aproveitei a situação para fazer algumas perguntas iniciais. Alan foi muito solícito, íamos conversando enquanto ele servia um prato, mexia nas panelas e algumas vezes respondia algo pontual para alguém. Contou que o coletivo surgiu de uma reunião de pessoas que trabalhavam no Café Bonobo ${ }^{6}$, como o próprio Alan, e na bicicletaria e café Vulp ${ }^{7}$, que já não está mais aberta, além de outras pessoas. Ambos os espaços compartilham um pouco dos ideais do Aurora, são antiespecistas (veganos) e de viés crítico e libertário. Quando perguntei das origens do sem preço, Alan falou 
que foi surgindo aos poucos: primeiro um bolo no Bonobo que era neste esquema, depois algumas experiências com a refeição toda que, pelo que entendi, foram se espalhando para outros lugares, como a Vulp. E assim o grupo foi se encontrando, aprendendo e se ensinando até que o coletivo se consolidou.

Depois perguntei como era para se manter economicamente, se as pessoas tinham outras rendas, se a proposta de transparência com a divulgação do balanço econômico sobre as mesas dava certo. Alan começou dizendo que "sempre que a gente se comunica diretamente, surte efeito”. Isso à primeira vista me pareceu sugerir algo geral sobre o coletivo se manter financeiramente com o restaurante, que dava certo. Isso estava correto, mas então a ideia de efeito tomou outro rumo e significado. Alan mencionou uma postagem realizada pelo coletivo no dia primeiro de abril falando da dificuldade de fechar as contas do mês de maio e pedindo apoio das pessoas que são parte de sua rede e frequentam seu restaurante. Isso gerou uma onda inesperada de ataques ao restaurante e mais especificamente ao sem preço, mas foi seguida de demonstrações de apoio. Alan disse que as pessoas do Coletivo nem se meteram na conversa. Não falamos muito mais sobre, não sabia o conteúdo exato. Mas isso evidentemente tinha afetado o pessoal do coletivo, o que me levou a buscar essa postagem e, mais à frente, dedicarei uma discussão somente tratando desse tópico. O caráter informal e o tom da conversa permitiram que eu demonstrasse minha apreciação pessoal ao projeto e falasse de experiências de ativismo em coletivos libertários e autonomistas de que participei. Do mesmo modo, Alan contou sua trajetória no movimento Punk Straight $E d g e^{8}$, aprendizados sobre alimentação entre Hare-Krishinas, viagens e organização de shows de pequena escala de bandas punk nacionais e internacionais.

Depois dessa ocasião, reenviei o e-mail com a proposta de pesquisa a pedido de Alan e, depois de uma resposta que eles iriam debater em reunião o assunto, marquei com Alan uma conversa na sexta-feira, dia 29 de junho de 2018, no fim do almoço. Disse que guardaria 
um prato de comida para mim. Cheguei na hora combinada, comi e fiquei esperando alguns minutos na poltrona ao lado do balcão de atendimento enquanto as pessoas trabalhando naquele dia iam organizando e limpando o restaurante. Alan logo veio me chamar para sentarmos numa mesa mais próxima à entrada. Depois de alguns minutos, Bianca se juntou a nós.

A primeira coisa que Alan comentou foi uma justificativa por terem demorado para marcarmos uma conversa. Disse que o coletivo não teve boas experiências com pessoas pesquisando, não retornavam e, além disto, tratavam o local como uma coisa estranha, 'alienígena' fora a palavra que usou. Mas, como já tínhamos conversado antes, falou que resolveu bancar com o coletivo. Explicou que normalmente, nessas situações, alguém acompanha mais de perto a pessoa fazendo a pesquisa. Disso implicava também que minha negociação teria que acontecer com as outras pessoas do coletivo individualmente caso quisesse, por exemplo, acompanhar o cotidiano ou tirar fotos. Isso nos levou ao assunto de ética na pesquisa, contei dos meus interesses, outras pesquisas e etc.

A colocação sobre o fato de o Aurora ser visto como 'alienígena' chamou minha atenção e foi fazendo mais sentido ao longo da conversa sobre as dinâmicas do cotidiano. Assim como qualquer outro estabelecimento do tipo, a rotina envolve trabalhos administrativos, preparação do cardápio, organização de horários e turnos, preocupação com alvarás, vistorias e impostos, idas ao CEASA, contato com fornecedores, produção e divulgação de material como o cardápio diário para alimentar as redes. Além disso, a principal renda de todos os integrantes vinha do restaurante. Ainda relataram como o projeto dependeu de um planejamento inicial bastante comprometido, já que fizeram um investimento e precisavam de uma projeção de recuperação. Naquele momento já estava quase alcançada. Disseram que acabando este momento de recuperar o investimento inicial poderiam começar a criar um fundo de 'emergência e férias', como previa o horizonte gerencial do projeto. 
Para o almoço, a maior entrada financeira do restaurante, além de duas pessoas ligadas ao coletivo, há sempre mais duas no regime de free-fixo, ganhando por dia, que são somente mulheres e homens em situação de 'vulnerabilidade social'. Estes e estas são parte das despesas normais do restaurante, ou seja, não são atingidas pelas marés baixas. Outros parceiros e parceiras ligadas ao movimento de moradores de rua tiveram apoio do coletivo para criar o Amada Massa ${ }^{9}$, um clube de pães que, além de fazer pães deliciosos, visa à construção de autonomia para pessoas que estejam ou estiveram em situação de rua. Começaram no espaço de uma 'facilitadora' que era integrante do coletivo, e agora têm o próprio espaço alugado e uma rede de assinantes mensais. Este caso reflete também uma intenção do projeto de colaborar com outros, até mesmo abrindo a cozinha algumas noites para coletivos parceiros ou causas específicas que requerem levantar algum dinheiro.

Outro elemento que poderia ser destacado no funcionamento do restaurante é o modo de divisão do lucro. Depois de descontadas as despesas com os mantimentos do estoque, com o aluguel, com impostos e com um fundo para 'emergências e férias' (o qual, na realidade, ainda não tinham conseguido começar a arrecadar), o dinheiro que sobra vai para o salário de cada membro do coletivo. Contudo, a divisão, assim como na questão do sem preço, não respeitava valores absolutos. Como Bianca descreveu, eles utilizam um método chamado 'pilha de dinheiro'. Todo o montante é colocado sobre a maior mesa (exatamente a que estávamos conversando) e juntos vão fazendo a distribuição entre si e outras pessoas, alguém que tenha trabalhado ou mesmo alguém externo que esteja precisando. A ideia é retirar dali o quanto cada um precisa para viver tranquilamente, mas 'sem luxos'. Argumentam que alguém pode acabar precisando de mais num certo momento. Nem toda retirada de dinheiro precisa ser justificada abertamente, apesar de me parecer implícito como este método passa por uma confiança e comunicação bastante afinada entre o coletivo. $\mathrm{O}$ importante é que só chega no fim quando todas as pessoas estiverem satisfeitas com a distribuição. 
Toda a dinâmica administrativa para o funcionamento do restaurante descrita por Alan e Bianca revela as necessidades de participar da infraestrutura regulada de consumo. Assim, em grande medida, tanto seguindo um conjunto de normas burocráticas e legais quanto nas suas rotinas de trabalho, expressam semelhanças com o funcionamento de qualquer restaurante. Mesmo se considerarmos a contratação de pessoas em situação de 'vulnerabilidade social' e a forma de divisão do lucro como aspectos organizativos destoantes de uma lógica comercial hegemônica, na experiência de cliente essas diferenças não são facilmente perceptíveis. Ficam nos bastidores, não na superfície. Outros estabelecimentos podem ter essas mesmas escolhas de gestão e não gerarem a percepção de 'alienígena'. Talvez não fosse exatamente isso o que Alan tinha em mente quando fez o comentário, mas como antropólogo, fico tentado a ponderar isso pela construção material de semelhanças e diferenças colocando paralelos com outras propostas.

Podemos pensar isso a partir do Bonobo, restaurante que o Alan cozinhava antes. Também é antiespecista (vegano), com direcionamento libertário e se localiza a poucas quadras do Aurora. Na sua página na internet, o coletivo explicita seu posicionamento político disponibilizando textos de questões que extrapolam a dimensão alimentar. Há um alinhamento de princípios que torna bastante plausível a escolha das mesmas formas de dividir os lucros e pensar no quadro de pessoas trabalhando ao administrar o restaurante. Porém, falar de aspectos nos bastidores implica pensar na extensão dos efeitos dessas escolhas para clientes. A única diferença que realmente grita para quem frequenta os dois restaurantes é o sem preço, já que no Bonobo há um preço pré-estabelecido para a refeição do dia. Sem dúvida haveria muitas outras nuances no processo administrativo (o coletivo é maior, tem uma rotina diferente de abrir o restaurante, normalmente o cardápio tem mais pratos). Contudo, o que me parece importante destacar para pensar em semelhanças e diferenças é ter em mente que as pessoas podem ir ao Bonobo e ter uma vivência semelhante a qualquer outro restaurante vegano na cidade, como o Prato 
Verde, localizado no bairro ao lado, que também tem um preço fixo, mas com um buffet e muito mais mesas se comparado aos outros dois.

O sem preço causa uma descontinuidade na experiência de comer num restaurante, não há dúvida, mas o comentário do tratamento 'alienígena' me sugere uma impressão de demasiado deslumbre a ponto de ofuscar dimensões que colocam o restaurante em paralelo com qualquer outro por suas rotinas, burocracias, dificuldades financeiras, fonte de renda e um sem fim de questões. Em certo momento de nossa conversa, Alan criou uma imagem brilhante ao falarmos das polêmicas ao redor do sem preço e seus efeitos: "É como um furo pequeno numa caixa d'água: não faz explodir, mas fica vazando".

Ao longo da conversa, ao tratar sobre o público que frequenta o restaurante, Alan e Bianca demonstraram, por exemplo, compreender como a localização próxima de bairros centrais de classe média, de outros circuitos ${ }^{10}$ de restaurantes veganos, feiras orgânicas, de certas casas de show, da universidade e de empresas da região é estratégica. Além disso, falaram da importância das redes sociais como divulgação, mencionando especialmente grupos de opções veganas e vegetarianas em Porto Alegre no Facebook, que atraia o interesse, compartilhamentos e algumas polêmicas envolvendo imagens e mensagens que, ao mesmo tempo que divulgam o cardápio do dia, em certos casos, tecem críticas a momentos na política e às violências estruturais contra seres humanos e animais.

Esse diálogo confirmou algo que intuía como frequentador, a aguda consciência quanto àquilo que viabiliza o projeto, e até em termos daquilo que na antropologia temos considerado infraestruturas; o papel da localização, dos circuitos de consumo e redes, das exigências legais e burocráticas, da internet e etc. Neste sentido, não são diferentes de qualquer proposta comercial que requer planejamento contando com despesas, objetivos, metas e todas as atividades rotineiras que descrevi acima, e que, em certo sentido, remetem ao processo de modelagem para seus usuários, neste caso clientes. $\mathrm{O}$ fato de o preço não ser pré-determinado não exclui os lugares comuns nos quais poderíamos 
notar o caráter de naturalização e invisibilidade emergindo. Um interessante exemplo dessa espécie de consciência infraestrutural é quanto ao papel da tendência contemporânea de "ecologização e politização do consumo" (Portilho 2010:549), especialmente envolvendo alimentos saudáveis, vegetarianismo e veganismo ${ }^{11}$. Mesmo que não tenha ficado completamente explícita essa percepção em nossa conversa, não é absurdo supor que seja algo reconhecido pelo coletivo e que torna a existência do restaurante e do sem preço possível. Talvez há 20 anos não fosse tão simples atrair público para opções de comida vegana.

Segundo Larkin, descrever uma infraestrutura é um "momento categórico" que "... abrange uma analítica cultural que destaca o comprometimento epistemológico e político envolvido em escolher o que é visto como infraestrutura (deste modo, causal) e o que é deixado de fora" (2013:330) ${ }^{12}$. Neste sentido, me parece pouco honesto descrever o Aurora sem levar em conta aquilo que não o torna alienígena e que, ao mesmo tempo, demonstra o comprometimento dentro de uma infraestrutura de consumo comparável a outros restaurantes. Nessa aproximação com o coletivo, pareceu-me que reconhecer isso não significa apagar o potencial crítico e político norteador, muito pelo contrário. Isso parecia abrir brechas e possibilidades que estão dentro do planejamento. Um caso interessante que exibe o potencial de encontrar brechas de atuação foi sobre um refugiado político que comia lá e muitas vezes não pagava, até que um dia chegou com uma quantia suficiente para compensar algumas refeições. Contou aos membros do coletivo que tinha conseguido um trabalho e agradeceu a eles. Isso pareceu ser algo corriqueiro na experiência deles, e eu mesmo já deixei de pagar uma vez ou outra por estar sem dinheiro e quando recebi compensei. Além disso, é normal encontrar pessoas em situação de rua no Aurora, seja como clientes comendo na mesa ao lado de outras pessoas visivelmente de classes médias altas, seja como parceiros e parceiras ou simplesmente amigos e amigas.

Aqui fica mais nítida a percepção das intenções práticas do sem preço para os membros do coletivo a partir de suas possibilidades. Em 
nossa conversa, eles me relataram um desejo que explicita ainda mais essa consciência infraestrutural. Disseram que se tivessem tempo e possibilidade, gostariam de ter dois restaurantes sem preço, um numa zona pobre e outro numa rica para que houvesse uma compensação. Se é evidente as intencionalidades críticas e políticas de todo o projeto, para Alan e Bianca me pareceu que nada é tão gratificante quanto valorizar o Aurora pelo que faz de melhor: a comida. A questão é que para ambos consumo e comida não estão isentos da política e da ideologia. Agora, construída uma descrição do projeto, vamos explorar com mais profundidade como o sem preço ganha sentido na experiência do cliente. E, assim, para lembrar a metáfora acima, como um furo pode criar uma inundação.

\section{A Infraestrutura 'que pensa' e a política do e no 'sem preço'}

Quando disse que o sem preço era a única coisa realmente idiossincrática na experiência de consumo no Aurora de modo algum quis reduzir sua potência, mas ponderá-la considerando uma gama de diferenças e semelhanças em relação a outras propostas, e assim não cair numa exotização exagerada (ou ver demasiada revolução?). Ao isolar esse elemento, podemos atentar para aquilo que é realmente proposto de transformação na relação do consumo, aquilo que não repete um itinerário burocrático que poderíamos dizer ser comuns a uma infraestrutura global de serviços: o estabelecimento decide o preço das mercadorias, cabendo ao cliente escolher e pagar. $O$ que essa experiência convida, como intencionalidade, é uma reflexão sobre o valor das coisas considerando a comida, o serviço, o projeto e a própria situação financeira de cada um (quanto eu pago normalmente para almoçar fora?). E estimular essa percepção sobre quanto valem as coisas parece ser algo notado no dia-a-dia pelo coletivo. Quando conversarmos, Alan e Bianca comentaram, por exemplo, sobre estudantes de escolas que muitas vezes deixam pouco dinheiro, o que sugeriram ser motivado pelo fato de essas crianças ainda não terem noção dos custos de fazer uma comida e oferecer um serviço; ou seja, há uma intenção 
explícita pela desnaturalização de uma atividade banal que é pagar por alguma coisa, fazendo de uma ação que normalmente ocorre quase irrefletidamente requerer reflexividade, relativização e ponderação de si. Não falaram de um restaurante normal na zona rica e outro sem preço na pobre. Apesar de haver uma ideia de compensação nesse sonho, mantem-se a intencionalidade.

Outra situação narrada que exibe o efeito de desnaturalização pretendido foi de uma senhora que, certo dia, entrou e perguntou como funcionava o restaurante. Ao saber que o preço era uma decisão dela mesma, e que não receberia uma sugestão de preço por parte do coletivo depois de insistir um pouco, ficou 'indignada e saiu'. Quando perguntei ao Alan e à Bianca como explicariam essa reação, disseram categoricamente que viam naquele desconforto a consciência de uma experiência que poderia implicar uma convivência dela, pagando 20 reais, e um morador de rua na mesa ao lado pagando 2 ou nada. Algo que seria injusto aos olhos dela, por isso algo indignante. Essa situação me surpreendeu e remeteu a outra que vivi na minha etnografia com caronas. Certa vez, enquanto pedia carona ao lado de uma parada de ônibus como de costume, uma senhora veio até mim e disse que não precisava pegar carona, ela pagaria minha passagem. Mantendo a atenção na passagem de carros, agradeci e respondi que até dinheiro. O transporte público em Florianópolis não ajuda, era mais fácil para mim chegar no meu destino de carona. Em ambas as situações é como se houvesse um curto-circuito ideológico que visibiliza os deslizamentos entre engajamento material e ideológico em atividades banais e irrefletidas. Existe um princípio na política democrática, na burocracia e nas infraestruturas no qual sempre nos coletivizamos numa igualdade de direito, então 4,20 é para todos os indivíduos. Há justeza a ser seguida, e ela deve estar presente na modelagem dos ambientes.

Frederico Neiburg (2007), a partir de uma etnografia sobre inflação no Brasil e na Argentina, propõe um projeto teórico interessante para essa reflexão: articular macroteorias econômicas e modelos com a experiência ordinária do dinheiro. De um lado economistas falando 
sobre como curar as moedas, conter a inflação e os vários modelos normativos, de outro, a realidade plural do uso e dos efeitos na vida das pessoas. Não é por acaso que esse argumento lembra a discussão sobre modelagem e engajamento com as infraestruturas, há uma convergência teórica no diálogo com a antropologia da ciência e os estudos de tecnologia. Sua abordagem articula o que chama teorias da 'performatividade' de Latour e Callon com as 'teorias nativas' com o trabalho de Daniel Miller (Miller 1998). Na introdução da coletânea de artigos organizada recentemente e intitula The Real Economy, Neiburg \& Guyer (2020) lançam um projeto intelectual que, além de primordialmente empírico sobre as existências plurais de engajamentos econômicos e noções de valor, é muito atento às continuidades, descontinuidades e deslizamentos entre o mundo dos experts e dos modelos com os usos ordinários. Voltemos ao caso empírico.

Numa postagem do dia primeiro de abril 2018, ainda na página do antigo Germina no Facebook, o coletivo relata que ao fecharem as contas do mês anterior se depararam com soma insuficiente para "cuidar minimamente da vida de seis pessoas" do coletivo e pediam apoio financeiro aos seus parceiros e parceiras ${ }^{13}$. A postagem trazia um gráfico simples em que o valor de 12.000 era "para que todas as pessoas do coletivo passem o mês minimamente confortáveis. Também cuida do nosso fundo de emergências"; 9.000 "para cobrir as necessidades básicas das 6 pessoas que compõem o coletivo e vivem desta ação; e os 5.980 "disponíveis para remuneração" naquele momento era um "valor insustentável" ${ }^{14}$. Vale comentar que havia uma greve de caminheiros e caminhoneiras no Brasil. E já que o transporte rodoviário é o principal meio de circulação de bens, faltava combustível nos postos, houve uma corrida louca aos supermercados para fazer estoques, paralisação de muitas atividades e, com isso, instalou-se um verdadeiro caos infraestrutural com efeito direto no setor de serviços.

A postagem gerou muito mais comentários (269), compartilhamentos (231) e reações (550) do que o normal no cotidiano do coletivo. Além dos apoiadores, houve muitos críticos: "Ué, vocês estão 
pedindo apoio financeiro? Pensei ter lido na descrição que vocês eram anticapitalistas", isso é uma "utopia delirante", já nos primeiros comentários. Outras manifestações infantilizavam a proposta e sugeriam uma ingenuidade por parte dos idealizadores e gestores do restaurante: agora seria o momento de crescer, sentir o que é a realidade, sugere-se abaixo. Uma pessoa menos sarcástica explicita como o que está em jogo nessas reações é uma concepção sobre a gestão do restaurante:

Justino: Essa ideia é fofa quando se faz por altruísmo. Se o negócio tem necessidade de ser integralmente autossustentável, e isso inclui pagar os funcionários/colaboradores/sócios/ etc... então é melhor adotarem a fórmula tradicional de todos os negócios que precisam lucrar para existir. Lucro não é pecado, é necessidade. ${ }^{15}$

Essas manifestações pressupõem uma incapacidade de gerir o restaurante, como se aquilo fosse um atestado de que estavam prestes a quebrar e fechar as portas, uma conclusão que, na minha opinião, não está atenta àquilo que fica pressuposto na postagem. Primeiramente, ao descreverem metas de remuneração com situações ideais e mínimas necessárias demonstram uma inteligência e controle em termos administrativos. Além disso, sabendo que o restaurante já existia há quase dois anos, fica muito explícito como até aquele momento a meta mínima para remuneração estava sendo de algum modo alcançada na maioria dos meses. Há um afastamento daquilo que de fato acontece ali a serviço de uma noção de como as coisas deveriam funcionar. Emprestando a ideia de Boltanski \& Chiapello (2009), podemos ver um esforço de 'justificação' do status quo do capitalismo e do que é a forma tradicional e hegemônica de planejar um negócio. E o mais interessante nestes comentários é que endereçam questões que transcendem a postagem. Mesmo não havendo nenhuma postura crítica explícita na postagem, tratava-se de algo bastante objetivo, ainda assim ela é reconhecida pelos comentários desta forma pela simples existência da proposta do sem preço. Daí vemos como um pequeno furo na caixa d'água pode provocar inundações, um curto circuito no conjunto dos mecanismos ideológicos que incita justificação. Até mes- 
mo em falas de pessoas mais próximas, pode-se reconhecer a estrutura argumentativa.

Leucócito: Gurias, assim.... Vocês pecaram na administração. Espero que sirva de aprendizado para os próximos empreendimentos. É um restaurante, oras, as pessoas pagam por uma alimentação diferenciada. Isto não vai afetar a causa, o arroz e o feijão continuam mais baratos do que a carne (grifos meus).

Quando levamos às últimas consequências a proposta de 'corresponsabilização e apoio mútuo' que dá sentido ao sem preço, não é difícil de chegar à conclusão de que esse apoio transcende uma situação específica de ambos os lados: a pessoa que pode comer e pagar mês que vem e o Aurora pode mobilizar sua rede num momento de aperto. A proposta explicitamente pretende a criação de vínculo com as pessoas que frequentam regularmente o restaurante, de modo que usar a infraestrutura digital para levantar essa grana é coerente com o plano de gestão. Em situações de crises, um negócio 'tradicional', como disse o amigo acima, vai mobilizar a rede de apoio bancária atrás de empréstimos por que essa é a solução no horizonte administrativo. Novamente, parece-me que a leitura da situação nessas manifestações perde de vista o histórico de existência do restaurante e aquilo que desde sua fundação se propõem a consolidar como estratégia de administrar e tocar um restaurante.

Essa reatividade gerada pela postagem - que de um lado lê a proposta como ingênua e, de outro, tece defesas à ordem de funcionamento capitalista apontando o método "tradicional" ou normal de administrar - ainda foi mais a fundo mobilizando teorias econômicas. Mais de uma pessoa trouxe para o debate noções declaradamente neoliberais sobre o 'preço ter uma inteligência', como defendeu Teumar. Para legitimar sua posição, compartilhou vídeos do filósofo Felipe Pondé, explicando por que 'tudo tem preço?' e falando de sua posição quanto ao veganismo ${ }^{16}$. Quando a discussão se intensifica e se aprofundam os debates com algumas pessoas, ele começa a postar links de artigos da página Instituto Mises Brasil, propagador do pensa- 
mento do teórico do neoliberalismo Ludwig Von Mises. Argumenta que o preço é parte de leis econômicas, como a lei da gravidade, de modo que eles só poderiam fracassar ao não utilizar essa 'ferramenta' da maneira correta. Esse comentário gerou 53 respostas, e Joséia foi uma das mais calorosas debatedoras. Posiciona-se não só numa defesa do restaurante, mas da importância do Estado para a sociedade, e é contra a ideia Estado mínimo proposta pelos autores e teorias que Teumar postava. $\mathrm{O}$ debate transcende em muito o problema em si; política de bem-estar social em diferentes países europeus, taxas tributárias, condições de salários e situações de hospitais públicos na Inglaterra. E estar nesse nível macro não os impedia (principalmente Teumar) de rapidamente retomar e contextualizar a proposta do sem preço em relação às teorias econômicas.

Neste caso, vemos de modo desenhado os deslizamentos da ponta do modelo à economia ordinária sobrepondo e cruzando ideias filosófico-econômicas, concepção administrativa e o ato de pagar. E este último, mesmo que distante em alguns momentos, era a aparente fonte de toda a reatividade e polêmica. Além disso, a mediação entre estes diferentes níveis gera seus próprios efeitos.

As autoras do instigante 'Gens: A Feminist Manifesto for the Study of Capitalism' chamam esses processos de 'dispositivos de conversão'. "The key power of these models in contemporary capitalism comes from their ability to erase particularity and sever objects, people, and resources from their contexts" (Bear et al 2015: sem página). Além disso, essas manifestações também evidenciam o grau de penetração da ideologia neoliberal na sociedade contemporânea. Como diria Pierre Bourdieu (1998), é uma teoria que se 'converte em verdade', num 'discurso forte' sobre como as coisas devem funcionar. Annelise Riles (2003), em uma etnografia sobre o mercado financeiro e neoliberalismo, também aponta nessa direção. Partindo de sua participação numa consultoria sobre a crise nuclear no Japão, coloca como seus contratantes esperavam que ela discutisse fatores culturais para explicar a situação de crise que justificariam o motivo pelo qual uma mega- 
companhia privada "era muito grande para cair", o que implica, como bem coloca a autora, traçar fronteiras duras entre dimensões política, econômica e cultural (Riles 2003:561) ${ }^{17}$. Este recurso argumentativo separando domínios não está, novamente, só no alto comando do mercado financeiro, na ideologia neoliberal ou nas teorias econômicas, mas circula de forma mais ampla na sociedade e no facebook.

Demétria: [...] sabe o problema de vcs, criaram a ideia q veganismo está atrelado a comunismo, anti capitalismo, sustentabilismo rsrs, raiva do dinheiro, ódio do sistema (eu tenho apenas da área frigorífico) o resto não me incomoda, não me permito utopias sem fundamento e revoltas q nada vão me acrescentar. Ao invés disso prego o amor aos animais e te garanto que sensibilizei muito mais pessoas do q vcs com esse papinho.

Essa intervenção explicita bem o esquema ideológico que busca estabelecer essas fronteiras a priori. Onde é política e onde é consumo, neste caso. Além disso, podemos ainda ponderar como essa colocação reflete o processo de politização do consumo em que vivemos no mundo contemporâneo, e que é também uma individualização e privatização da ação política, como argumenta Portilho (2010:563) partindo de um estudo sobre a autoatribuição de responsabilidade entre consumidores de uma feira orgânica no Rio de Janeiro. Neste sentido, é possível enquadrar este fenômeno no movimento de renovação do 'espírito capitalista' motivado pelas críticas e parte das reestruturações dos arranjos ideológicos de justificação. Porém, em vez de noções sobre administração como o estudo de Boltanski \& Chiapello (2009), trata-se das noções de consumo, que afinal também é um engajamento no capitalismo.

No meu período frequentando o restaurante e nas interações com o pessoal do coletivo, fiquei com a impressão de que, antes de buscarem reconhecimento externo sobre sua postura política e iniciativas, interessa-lhes mais preparar e servir uma boa comida. Certa vez comentaram sobre um senhor, ex-militar, que, mesmo sendo crítico do estilo de vida (mencionando tatuagens, piercings e pelos) e das opções 
políticas do coletivo, elogiara muito a comida. Souberam disso por uma amiga e reforçaram que esse tipo de elogio era o que os deixava mais felizes. Porém, não acaba aí. Se o restaurante, sim, figura como local de trabalho, fonte de remuneração para os membros do coletivo e para as outras pessoas que colaboram com essa rotina, isso não significa que as fronteiras bem definidas entre o trabalho, a gestão administrativa, política e comida devam existir da forma como são mobilizadas. Essa pureza pretendida pela performatividade dos modelos mobilizada nos comentários não cola para eles. E aqui vale retomar o argumento da seção anterior quanto à consciência do posicionamento numa cadeia ou redes de infraestruturas permitir vislumbrar formas de ação e engajamento específicos. Além disso, as paredes do restaurante têm o objetivo de abalar essas fronteiras. A decoração com bandeiras, desenhos e charges, em sua grande maioria, tecem críticas mais ou menos diretas ao machismo, à violência animal e outras violências estruturais. Contaram-me que o restaurante fora concebido para que 'as paredes pensassem'.

Isso também acontece com algumas das criativas chamadas para almoço ou janta nas redes sociais. Juntos às informações do cardápio do dia, a logo e o 'sem preço', montagens com imagens e textos tecem críticas (não sem ironia) à produção frigorífica, ao armamento, ao desastre com a barragem de Brumadinho-MG, descaso com as vítimas e muitas outras polêmicas na vida pública e política do mundo e do país. Numa destas ocasiões, depois que um proeminente representante político no congresso fez uma apologia à ditadura militar, a chamada utilizava uma imagem com uma mulher sendo torturada e gerou um comentário de alguém que disse ser fã da comida, mas que a divulgação 'não caiu bem'. Numa resposta de Alan no seu perfil pessoal, ele contextualiza a imagem como um abuso e uma violência institucionalizada chocantes, e aponta como a cena forte também provocou desconforto nele, mas disse que, como de costume, utilizava o seu principal meio de divulgação - que era por meio dos almoços que faz - para ilustrar desigualdades e abusos. 
Mas, novamente, é diferente do sem preço por ser algo que pode ser visto como motivado pelos bastidores, não necessariamente passam pelo cliente. Se pensamos dimensão jurídica de um restaurante do coletivo, é uma decisão individual, que, apesar de tencionar essas fronteiras, não gera a escala de reação como a polêmica do sem preço. Pode-se até considerar como estratégia direcionada para um público específico, não que ache que o coletivo pense nisso neste caso. A questão é que o sem preço é diferente disso. Não é só o auge dessa estratégia de abalar supostas neutralidades entre ação política, trabalho e comida. É interessante notar como eles tratam o sem preço como uma 'prática', o que remete a um paralelo potente com teorias sociais. Em contraposição ao conceito de habitus, essa ideia propõe uma atividade em que a capacidade de agir (agency) fica em foco, e junto dela a reflexividade subjetiva e as incertezas emergem (Bourdieu 1991; Ortner 2007). Ela obriga clientes a pensarem, a fazerem do ato de abrir a carteira algo refletido e, consequentemente, tende a visibilizar as cadeias produtivas, circulações, efeitos do dinheiro e os comprometimentos ideológicos que isso implica.

\section{Visibilizando a política nas e das infraestruturas}

O caso do Aurora e a prática do sem preço traz alguns desdobramentos em relação aos jogos entre (in)visibilidade e colapso na discussão antropológica das infraestruturas. Diferente do tipo de imagem clássica evocada pela quebra de cano de abastecimento de água ou de um transformador numa usina de eletricidade que faz com que se perceba a extensão material, no caso dessa experiência o colapso e a visibilização emergem num nível mais sutil, ideológico e até perspectivo, em que uma gama de posições singulares e variadas sobre a existência ou não de uma crise, uma iminente falência e o que deve ser ou não visibilizado se revelam. E isso não implica uma espécie de relativismo cultural no qual cada pessoa teria sua versão sobre uma realidade material e objetiva compartilhada por todos e todas. Assim como a viabilidade do projeto depende de um arranjo material para ocorrer, 
como busquei explicitar a partir de aspectos da gestão administrativa, a projeção de sustentabilidade e redes que são mobilizadas, também o efeito pretendido de desnaturalização desta parte do itinerário de consumo depende dessa organização material. Star (1999) já havia chamado atenção ao fato de que as infraestruturas podem ter diferentes significados, como uma escada que pode ser ao mesmo tempo algo invisível para uma pessoa, uma barreira para uma pessoa cadeirante e um “tópico” para um arquiteto (Star 1999:380). A questão que este caso empírico me parece iluminar e contribuir nesta discussão é como a própria crise, quebras, colapsos e (in)visibilidade podem ser também perspectivos.

Assim, levando-se em consideração o sem preço ser uma prática que propõe uma maneira heterodoxa de realizar algo comum e banal, ela tem a potência de criar curtos-circuitos ideológicos em princípios e diretrizes norteadores das infraestruturas e anexadas à sua materialidade. Um destes, bastante evidente na intencionalidade desta proposta, é a ideia de justeza da impessoalidade. A indignação da senhora ao não aceitar comer ali sem no mínimo uma sugestão no caso relatado por Alan e Bianca pode ser compreendida nesta direção. Semelhante a algumas questões provocadas numa pesquisa anterior com prática de caronas num contexto urbano, também uma forma heterodoxa de fazer algo banal, o engajamento material parece ativar as pessoas na sua diferença ao invés das medidas que os igualam por meio do dinheiro. Paradoxo no discurso político emergido disso: apesar de qualquer pessoa concordar que o dinheiro é um potente marcador de diferenças (neste caso diferenças normalmente chamadas de desigualdade), acredito que grande parte delas se expresse e haja de modo a se comprometer com a ideia de justiça na igualdade do preço pago por algo. Fazemos isso por simplesmente abrir a carteira, ativamos esses princípios mais gerais que nos coletivizam numa sociedade individualista. Contudo, ao invés de nos coletivizarmos entrando em relação com outras pessoas simplesmente pagando como todos e todas, no caso do sem preço somos convidados a fazê-lo através de aspectos mais 
relativos e singulares. E essa ideia merece uma nota teórica: em todos os modelos, sejam infraestruturais, teóricos de economia ou ciência política, ou mesmo num comércio de porcos na Melanésia (Strathern 2014), podemos retirar considerações sobre o que coletiviza e o que individualiza as pessoas, processos em que relações são objetificadas e obviadas, e outros em que são abertas e exibidas. Quando contrastados com as práticas reais, divisões duras e absolutas entre essas duas dimensões se provam mais parte de regimes ideológicos (Wagner 2009) e, consequentemente, mais parte das intencionalidades performativas do que algo de uma pretensa realidade objetiva.

Antes de encerrar esta conclusão, parece-me apropriado alguns comentários sobre política. A literatura antropológica contemporânea sobre infraestruturas, em sua grande maioria, capta um sentido de política muito evidente ligado às formas de governo na gestão e na construção dessas materialidades, algo que muitas vezes passa por evidenciar relações impróprias entre Estado e empresas privadas (Knox $\&$ Harvey 2015), conflitos existentes em torno dessas infraestruturas (Dalakoglou 2010), a sobreposições de agendas de desenvolvimento urbano, expansão capitalista e da cidadania (Graham \& Marvin 2001) e nos efeitos de sujeição dos engajamentos. Acredito que o caso do Aurora evidencia uma política a ser realizada nos detalhes, nas pequenas transgressões de certas lógicas que se sustentam no tempo exatamente por sua organização material. Neste sentido, é interessante notar como o sem preço é uma prática com finalidade muito objetiva, na qual não necessariamente há uma ação política consciente. Acredito que para muitos e muitas frequentadoras do Aurora, este caráter não é o principal motivador de comer ali. Porém, sendo primordialmente objetiva, sua existência é provocadora, motiva opiniões, mobiliza outros discursos. Um desses pode ser o deslumbre apaixonado e idealista da transformação e de crítica social que algumas pessoas tendem a enfatizar em detrimento de uma atenção às determinantes ligadas ao fato dessas práticas estarem no meio de um mundo compartilhado com muitas pessoas e inserido em circuitos de consumo e redes maio- 
res. Uma espécie de inflação da crítica. Por outro lado, pode mobilizar defesas do status quo de como as coisas devem funcionar, o que é tradicional, correto e etc. Claro, esta contraposição é preenchida de meios termos que exibem a complexidade das subjetividades e engajamentos. Contudo, (e aí acredito estar o potencial heurístico desta abordagem) pelo efeito de contraste evocado, é possível mergulhar em objetos de reflexão que são difíceis de serem pesquisados por sua falta de relevo e de riqueza se pensado como práticas específicas. Milhões de reflexões teóricas e filosóficas sobre o ato de pagar são possíveis, mas fazer uma etnografia focado nesse ato não é fácil. É demasiado simples, plano. Não à toa a Teoria da Compra de Miller (1998) vai enfatizar o que motiva a compra antes dela em si. É um ato para além da compra.

Graham \& Marvin (2001), ao discutir a infraestrutura urbana, apontam como o caráter banal e normalizado das interações com as infraestruturas apertando a descarga no banheiro, acendendo uma luz e pondo o lixo na rua é um dos motivos da negligência desta temática nas reflexões das ciências humanas sobre a cidade (Graham \& Marvin 2001:21). Pagar por algo se assemelha a isso. É tão burocrático que remete ao que David Graeber chamou de 'zonas mortas da imaginação' (2006) se referindo a áreas de simplicidade, falta de relevo de significados, confusão e até estupidez nas relações com as burocracias. O autor diz que se revelam "formas omnipresentes de violência estrutural que definem as próprias condições da nossa existência" (Graeber 2006:105). São "áreas de simplificação violenta” (Graeber 2006:106), "projetadas para serem simples e autocontidos ao máximo" (Graeber 2006:109) ${ }^{18}$, o que contrasta com a riqueza simbólica e abertura de significados dos dramas rituais, poéticas dos espaços, manifestações artísticas e outros objetos estimulantes ao trabalho interpretativo e analítico para o qual nós antropólogos somos treinados (Graber 2006:106). Assim, demonstra-se certa "[...] tendência de identificar o que é interessante com o que é importante, e assumir que áreas de densidade são áreas de poder. $\mathrm{O}$ poder da burocracia mostra exatamente como 
este nem sempre é o caso" (Graber 2006:111) ${ }^{19}$. Se a prática do sem preço tem a potência de nos falar da política das infraestruturas de que somos todos cúmplices, discutida por muitas autoras e autores, também nos convida a pensar como há uma política a ser feita nas infraestruturas, nos detalhes do engajamento, na atenção para os efeitos. Para lembrar a epígrafe que abre este artigo, "a verdadeira estrutura de poder organização de poder é a organização material, tecnológica e física deste mundo" (Comitê Invisível 2016:102).

\section{Notas:}

1 Agradeço aos membros dos coletivos Aurora e Germina, em especial Alan Chaves e Bianca Rabello, por compartilhar suas experiências e maravilhosas comidas. Agradeço também ao colega Gabriel Brito pelos valiosos comentários nas versões finais deste artigo.

2 A partir de agora farei o uso sem aspas e sempre em referência à proposta.

3 Fonte: material informativo distribuído pelo restaurante

4 Este ponto remete à reflexão dos trabalhos invisíveis no desenvolvimento científico de Donna Haraway (2004:223). Na reflexão de Star, a questão de como a infraestrutura impõe uma narrativa "...que não problematiza a diversidade" (Star 1999:348) pode trazer paralelos interessantes com a ideia de 'testemunha modesta' do avanço científico: o homem branco de classes altas para que não vê o esforço de diferentes pessoas que não o cientista.

5 O dinheiro pode ser visto como tendo também sua própria infraestrutura com as casas de moedas, casas de câmbio, produção de índices e etc. Agradeço ao Gabriel Brito pela lembrança.

6 Também localizado no bairro Bom Fim, o café é gerido por um coletivo de 10 pessoas que se autodenominam antiespecistas e libertários. Muitas das ideias parecem se alinhar com o Germina, administração horizontal entre os membros do coletivo, não utilizam cartões de crédito, tem comida vegana e se apresenta como mais do que um restaurante ou café. No site do Bonobo há livros de receitas criados pelo coletivo, e outros textos de caráter crítico libertário do próprio coletivo e de outras pessoas, tudo livre de direito autoral (http://www.cafebonobo.com.br).

7 https://www.facebook.com/vulpbicicafe/.

8 É um subgênero do Punk que defende veganismo e abstenção de qualquer tipo de drogas. Maganini (2014) menciona em seu estudo sobre circuitos em São Paulo 9 Website: https://amadamassa.com.br.

10 Magnani (2014) para um conceito mais amplo e Zelizer (2005) para um olhar mais restrito aos circuitos econômicos. 
$11 \mathrm{O}$ as redes do slow food no Brasil é exemplo disso (Shineider 2015).

12 Tradução minha: "The act of defining an infrastructure is a categorizing moment. Taken thoughtfully, it comprises a cultural analytic that highlights the epistemological and political commitments involved in selecting what one sees as infrastructural (and thus causal) and what one leaves out" (Larkn 2013: 330).

13 Assumo aqui um tratamento incompleto metodologicamente sobre internet e redes sociais, porém justifico a ausência pelo escopo do artigo e pela interessante maneira com que o objeto de reflexão, o sem preço, emerge: são comentários e relações espontâneas e reativas a uma situação. Quando tentei perguntar para algumas pessoas enquanto estava no Aurora as reações tendiam a ser vagas.

14 Postagem do dia primeiro de abril na página do Germina-https://www.facebook.com/ColetivoGermina/photos /a.279063739179045.1073741829.242980322787387/454114801673937/?type $=3 \&$ theater.

15 Os nomes dos entrevistados foram alterados para guardar a privacidade.

16 'Tudo tem preço' - Luiz Felipe Pondé (https://youtu.be/g3bkzbE6dFU) e 'O que eu acho do Veganismo' - Luiz Felipe Pondé (https://youtu.be/93kQeN6w9Es).

17 Muito debate tem sido realizado sobre as ideias neoliberais e América Latina (Ganti 2014; Boas \& Gans-Morse 2009). Para uma análise no Brasil entre os 70 e os 2000, ver a tese de Denise Barbosa Gros (2003). A autora mapeia os institutos neoliberais, suas principais ideias e vínculos com outras instituições políticas, econômicas, jurídicas, midiáticas e educacionais.

18 "[...] designed to be maximally simple and self-contained" (Graeber 2006:109).

19 Tradução minha do original: "We also have an increasing tendency to identify what's interesting with what's important, and to assume places of density are also places of power. The power of bureaucracy shows just how much this is often not the case" (Graeber 2006:111).

\section{Referências:}

BEAR, L. et al. 2015. Gens: A feminist manifesto for the study of capitalism. (https://culanth.org/ fieldsights/652-gens-a-feminist-manifesto-for-the-studyof-capitalism; acesso 03/06/2020).

BOAS, T. C. \& GANS-MORSE, J. 2009. "Neoliberalism: From New Liberal Philosophy to Anti-Liberal Slogan". Studies in Comparative International Development, 44(2):137-161.

BOLTANSKI, L. \& CHIAPELLO, É. 2009. “'O capitalismo e seus críticos'. O novo espirito do capitalismo. São Paulo: Martins Fontes.

BOURDIEU, P. 1998. A essência do neoliberalismo. Contrafogos: táticas para enfrentar a invasão neoliberal. Zahar: Rio de Janeiro.

. 1991. The Logic of Practice. Stanford: Stanford University Press. 
COMITÊ INVISÍVEL. 2016. Aos nossos amigos: crise e insurreição. São Paulo: n-1 Edições.

DALAKOGLOU, D. 2010. "The road: An ethnography of the Albanian-Greek cross-border motorway”. American Ethnologist, 37(1):132-149.

GANTI, T. 2014. "Neoliberalism”. Annu. Rev. Anthropol, 43:89-104.

GRAHAM, S. \& MARVIN, S. 2001. Splintering Urbanism: networked infraestructures, technological mobilities and the urban condition. Routledge: London and New York.

GRAEBER, D. 2012. "Dead zones of the imagination: On violence, bureaucracy, and interpretive labor". HAU, Journal of Ethnographic Theory, 2(2):105-28

GROS, D. 2003. Institutos Liberais e neoliberalismo no Brasil da Nova República. Tese de Doutorado. Porto Alegre: Fundação de Economia e Estatística Siegfried Emanuel Heuser.

HARAWAY, D. 2004. "Modest_Witness@Second_Millennium”. In HARAWAY, D. (ed.): Haraway Reader, pp. 223-250. New York: Routledge.

HARVEY, P. \& KNOX, H. 2015. Roads. An Anthropology of Infraestructure and Expertise. Ithaca and London: Cornell University Press.

HERZFELD, M. 1992. The social production of indiference. Exploring the symbolic roots of Western bureaucracy. Chicago and London: The University of Chicago Press.

LARKIN, Brian. 2013. "The Politics and Poetics of Infraestructure". Annu. Rev. Anthropol., 42:327-43.

MAGNANI, J. G. 2014. “O Circuito: proposta de delimitação da categoria”. Ponto Urbe, 15. (http://journals.openedition.org/pontourbe/2041; acesso em 24/06/2020).

MILlER, D. 1998. A Theory of Shopping. Cambridge: Polity Presss. . 2007. "Consumo como cultura material". Horizontes Antropológicos, $13(28): 33-63$.

NEIBURG, F. 2007. "As moedas doentes, os números públicos e antropologia do dinheiro". Mana, 13(1):119-151.

NEIBURG, F. \& GUYER, J. 2020. "Introduction: The real in the real economy". In NEIBURG, F. \& GUYER, J. (eds): The Real economy, Essays in ethnographic theory, pp. 1-27. Chicago: Hau Books.

ORTNER, S. B. 2007. "Subjetividade e crítica cultural". Horizontes Antropológicos, 13(28):375-405.

PORTILHO, F. 2010. "Self-attribution of responsibility: consumers of organic foods in a certified street market in Rio de Janeiro, Brazil". Etnográfica, 14(3):549-565.

RILES, A. 2003. "Market Collaboration: Finance, Culture, and Ethnography after Neoliberalism”. American Anthropologist, 115(4):555-569.

SCHEGLOFF, E. A. 2006. "Interaction - The Infrastructure for Social Institutions, the Natural Ecological Niche for Language, and the Arena in Which Culture is Enacted”. In ENFIELD, N. J. \&Levinson, S. C. (eds.): Roots of Human Sociality: Culture, cognition and interaction, pp: 70-69. London: Berg. 
SCOTT, J. 1998. Seeing Like a State. How Certain Schemes to Improve the Human Condition Have Failed. New Haven/ London: Yale University Press.

STRATHERN, M. 2014. "Sujeito ou Objeto? As mulheres e a circulação bens de valor nas terras altas da Nova Guiné”. In STRATHERN, M. (ed.): O Efeito Etnográfico e outros ensaios, pp.109-133. Cosac Naify: São Paulo.

SHINEIDER, K. 2015. A revolução está no prato: do global ao local no movimento slow food. Dissertação de mestrado. Florianópolis: Universidade Federal de Santa Catarina.

SIMMEL, G. 2005. "As grandes cidades e a vida do espírito". Mana, 11(2):577-591.

SMITH, M. L. 2016. "Urban infrastructure as materialized consensus". World Archaeology, 48(1):164-178.

STAR, S. L. 1999. "The Ethnography of Infrastructure”. American Behavioral Scientist, 43(3):377-391.

WEBER, M. 1974. "Burocracia”. In GERTH, H.H. \& MILLS, C. W. (eds): Ensaios de sociologia, pp. 229-282. Rio de Janeiro: Zahar Editora.

\begin{abstract}
This article analyzes the act of paying from the anthropological perspective on infrastructure. More specifically, the argument relies on its conceptual tools that point out the ordinary, banal and invisible dimension in which infrastructures are revealed to people in their daily interactions. This reflexive exercise is enriched by an empirical case that this bureaucratic consumption itinerary, paying for something, is organized in a different way: a restaurant in which the meal does not have a fixed, pre-set or even suggested price. The Aurora proposes the 'sem preço' (without price) as a practice of 'co-responsibility and mutual support' based on the understanding that money has different values in our society for each person. The contrasting effect this experience engages allows us to deepen the understanding about our naturalized commitments to the logic of the functioning of infrastructures through the constant exchange between materiality and ideology in which we are always agents and subjects.
\end{abstract}

Keywords: Infrastructure, Daily Life, Money, Consumption, Political Action.

Recebido em outubro de 2020. Aprovado em dezembro de 2020. 